\title{
High-Throughput Microarray-Based Enzyme-Linked Immunosorbent Assay (ELISA)
}

BioTechniques 27:778-788 (October 1999)

\author{
L.G. Mendoza, P. McQuary, \\ A. Mongan, R. Gangadharan, \\ S. Brignac and M. Eggers \\ Genometrix, The Woodlands, \\ TX, USA
}

\section{ABSTRACT}

A new generation biochip is described as capable of supporting high-throughput (HT), multiplexed enzyme-linked immunosorbent assays (ELISAs). These biochips consist of an optically flat, glass plate containing 96 wells formed by an enclosing hydrophobic Teflon ${ }^{\circledR}$ mask. The footprint dimensions of each well and the plate precisely match those of a standard microplate. Each well contains four identical 36-element arrays (144 elements per well) comprising 8 different antigens and a marker protein. Arrays are formed by a custom, continuous flow, capillary-based print head attached to a precise, high-speed, $X-Y-Z$ robot. The array printing capacity of a single robot exceeds 20000 arrays per day. Arrays are quantitatively imaged using a custom, high-resolution, scanning charge-coupled device (CCD) detector with an imaging throughput of 96 arrays every $30 \mathrm{~s}$. Using this new process, arrayed antigens were individually and collectively detected using standard ELISA techniques. Experiments demonstrate that specific multiplex detection of protein antigens arrayed on a glass substrate is feasible. Because of the open microarray architecture, the 96-well microarray format is compatible with automated robotic systems and supports a low-cost, highly parallel assay format. Future applications of this new highthroughput screening (HTS) format include direct cellular protein expression profiling, multiplexed assays for detection of infectious agents and cancer diagnostics.

\section{INTRODUCTION}

In recent years, DNA biochips composed of densely packed probe arrays have revolutionized genetic analysis and discovery by highly multiplexed, miniaturized, molecular assays. These tools have been used for numerous molecular assays including highthroughput (HT) genotyping (5), differential gene expression $(8,9)$, mutation detection and DNA sequencing (1). For nearly twenty-five years, enzymelinked immunosorbent assay (ELISA)based immunoassays have been the mainstay of the diagnostic tests used for the detection of infectious disease. In more recent times, numerous researchers have refocused their attention on the continuing evolution of ELISAbased formats and have begun to explore miniaturized, highly multiplexed, microarray formats $(2-4,6,7,10)$. In DNA-based arrays, high specificity is provided by Watson-Crick base pairing between complementary sequences under appropriate salt conditions using either oligonucleotide or cDNA-length probes. Alternatively, in a standard ELISA, specificity between antigen and antibody is governed by high affinity associations between an epitope on the antigen and its cognate binding site on the Fab portion of an IgG. The main challenge in developing a microarraybased ELISA is minimizing nonspecific cross-reactivity between numerous antigen and antibody mixtures, thus maintaining the integrity of the assay. In this study, we demonstrate the feasibility of simultaneously and specifically detecting numerous antigens using a 96-well, microarray-based ELISA. The specificity and sensitivity of this new ELISA format is discussed.

\section{MATERIALS AND METHODS}

All antigens and their corresponding biotin-labeled monoclonal antibodies were purchased from Sigma (St. Louis, MO, USA). Lyophilized antigens were reconstituted as recommended by the manufacturer to a concentration of 10 $\mathrm{mg} / \mathrm{mL}$ in $1 \times$ phosphate-buffered saline (PBS) (pH 7.4). Biotinylated monoclonal antibodies came pre-dissolved in $0.1 \mathrm{M}$ sodium phosphate ( $\mathrm{pH} 7.4$ ) containing $1 \%$ bovine serum albumin (BSA). All antibody solutions were divided into aliquots and stored at $-20^{\circ} \mathrm{C}$. Streptavidin-alkaline phosphatase conjugates were purchased from Boehringer Mannheim (Indianapolis, IN, USA). Blocker ${ }^{\mathrm{TM}}$ Casein in PBS was purchased from Pierce Chemical (Rockford, IL, USA). Fluorescent alkaline phosphatase substrate $\left(\mathrm{ELF}^{\circledR}\right)$ was purchased from Molecular Probes (Eugene, OR, USA). Print capillaries (100$\mu \mathrm{m}$ diameter) were purchased from J\&W Scientific (Folsom, CA, USA)

Optically flat, teflon-coated, 96-well glass microscope plates were manufactured by Erie Scientific (Portsmouth, NH, USA). Aminopropyltrimethoxysilane (APTS) was purchased from Aldrich Chemical (Milwaukee, WI, USA). Bis-sulfo-succinimidyl suberate $\left(\mathrm{BS}^{3}\right)$ was purchased from Molecular BioSciences (Boulder, CO, USA).

\section{6-Well Microarray Plate Manufacturing}

All glass plates were cleaned ultrasonically in succession with a 1:10 dilution of detergent in warm tap water for 5 min in Aquasonic Cleaning Solution (Catalog No. 21811-894; VWR, West Chester, PA, USA), multiple 
Table 1. Array Antigens Consist of Purified IgGs from Various Sources

\begin{tabular}{|c|}
\hline Antigens \\
\hline Goat IgC \\
Rat IgG \\
Cat IgG \\
Human IgG 4 \\
Bovine IgG \\
Rabbit IgG \\
Chicken IgG \\
Guinea Pig IgG \\
Biotinylated BSA \\
The proteins were dissolved in 50 \\
$\mathrm{mM}$ carbonate buffer (pH 8.3 ) at 100 \\
$\mu \mathrm{g} / \mathrm{mL}$ and printed on the 96 -well \\
microarray plate using the capillary \\
array printer. Additionally, a twofold \\
serial dilution of rabbit IgG corre- \\
sponding to $100 \mu \mathrm{g} / \mathrm{mL}, 50 \mu \mathrm{g} / \mathrm{mL}$, \\
$25 \mu \mathrm{g} / \mathrm{mL}, 12.5 \mu \mathrm{g} / \mathrm{mL}$ and 6.25 \\
$\mu \mathrm{g} / \mathrm{mL}$ was also made and printed in \\
the same array alongside the above \\
proteins.
\end{tabular}

rinses in distilled water and $100 \%$ methanol (HPLC grade) followed by drying in a class 100 oven at $45^{\circ} \mathrm{C}$. Clean glass plates were chemically functionalized by immersing the plates in a solution of APTS $(5 \% \mathrm{vol} / \mathrm{vol}$ in absolute ethanol) for $10 \mathrm{~min}$. Plates were then rinsed in $95 \%$ ethanol, allowed to air dry and heated at $80^{\circ} \mathrm{C}$ in a vacuum oven for $2 \mathrm{~h}$ to cure. Individual amino-derivitized wells were then reacted using $40 \mu \mathrm{L}$ of a $5 \mathrm{mg} / \mathrm{mL}$ solution of $\mathrm{BS}^{3}$ in $1 \times \mathrm{PBS}(\mathrm{pH} 7.4)$ for 20 min at room temperature (RT). The $N$ hydroxysuccinimide (NHS)-activated glass surface was rinsed with distilled water and placed in a $37^{\circ} \mathrm{C}$, dust-free, class 100 oven for 15 min to dry. Dry activated plates were stored desiccated for up to 6 weeks before using.

\section{Microarray Printing}

The microarray printer consists of a 36-capillary array print head mounted to a high resolution $\mathrm{X}-\mathrm{Y}-\mathrm{Z}$ positioning robot. The robot-mounted capillary print head consists of 36 capillaries precisely

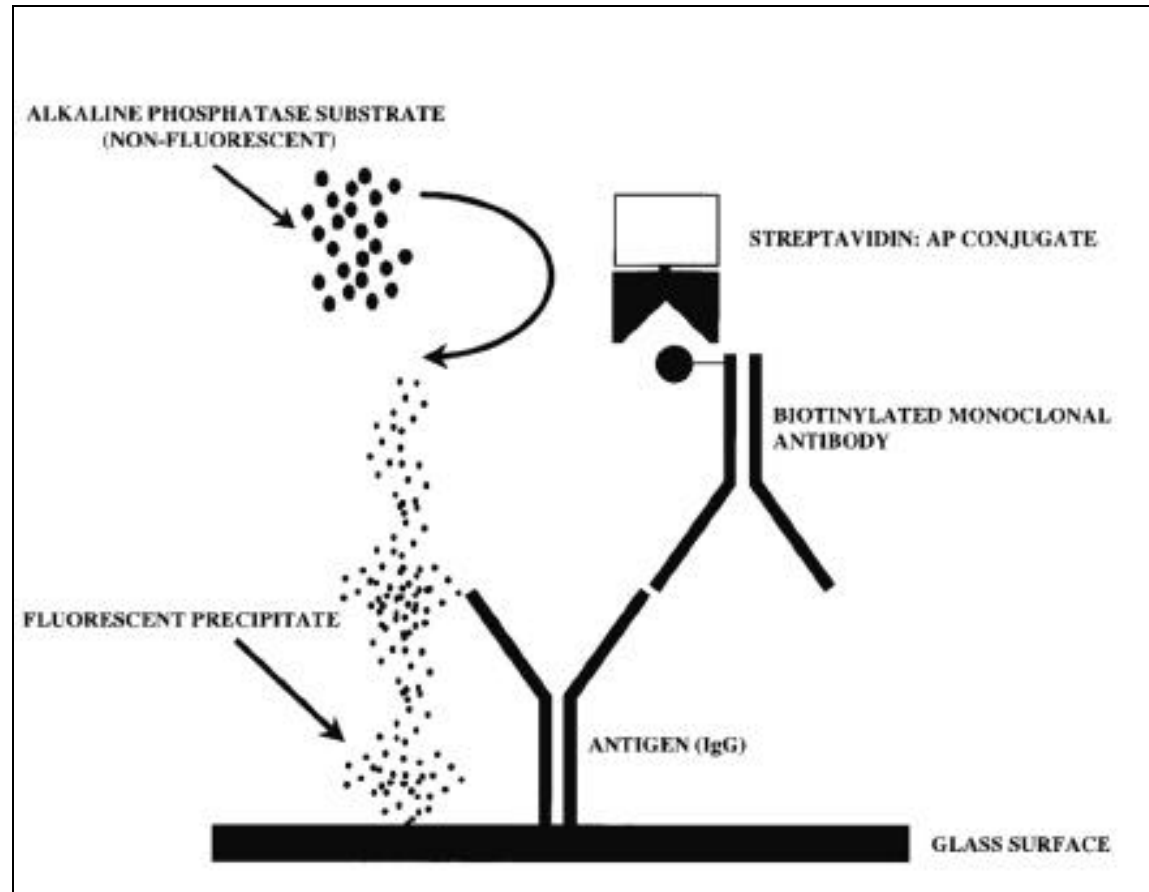

Figure 1. Schematic representation of indirect ELISA format used to detect protein arrays. The attachment substrate is optical quality glass that has been functionalized to bind proteins using a homobifunctional NHS-ester. Protein antigens consisting of purified IgGs are immobilized on the activated glass surface. Surface antigens are detected using a biotin-labeled primary monoclonal antibody specific for each antigen in the array. All primary antibody-binding events are indirectly detected using a streptavidin-alkaline phosphatase conjugate and ELF. arranged as a square $6 \times 6$ array. This print head can simultaneously and precisely deliver in a continuous manner up to 36 different solutions $(200 \mathrm{pL}$ per spot) to any flat surface and can be expanded to 256 fluids as needed. Each $6 \times$ 6 array occupies an area of $3.24 \mathrm{~mm}^{2}$. Individual array elements had a diameter of approximately $275 \mu \mathrm{m}$ with a centerto-center spacing of $300 \mu \mathrm{m}$.

As illustrated in Figure 2, each capillary on the print head originates from a standard 96- or 384-well plate contained within a pressurized manifold. Print solutions are first aliquoted into designated wells in the microplate and then placed inside the manifold assembly. Precise fluid delivery to the glass surface is initiated and maintained through the capillaries by a custom, computercontrolled pressure regulator. Before initiating the print process, the capillaries are primed with solution, and flow to each capillary is verified by contact printing on water-sensitive print paper (Spraying Systems, Wheaton, IL, USA). After each plate is printed, protein solutions are allowed to dry on the surface of the 96-well plate. Array quality is rapidly confirmed in each well by nondestructively imaging the dried proteinsalt crystals using the high-resolution charge-coupled device (CCD) camera with ambient room-light illumination. The size, uniformity and absence/presence of crystals can be determined using this simple quality control test.

The set-up time needed to initiate a specific print job is typically $30 \mathrm{~min}$. Once the printer is primed, thousands of identical arrays can be rapidly and sequentially produced using this continuous contact process. After a print run is complete, it requires approximately 20 min to flush out the capillary lines before reinitiating the system for another print job.

Depending on the type of print head mounted to the robot, this instrument is capable of printing a $16 \times 16$ element array every second. At these rates, approximately 3500 arrays can be printed every hour using a single robot. This high-throughput robot printer can be used to deposit DNA-, RNA- or protein-based solutions. The microarray printing process is very efficient, requiring a single milliliter of antigen solution to print more than 5 million 
arrays, based upon a standard spot volume of approximately $200 \mathrm{pL}$.

\section{Preparation of Antigen and Antibody Solutions}

Each antigen stock (either 10 $\mathrm{mg} / \mathrm{mL}$ or $1 \mathrm{mg} / \mathrm{mL}$ in PBS) was diluted into $50 \mathrm{mM}$ carbonate buffer $(\mathrm{pH}$ $8.3, \mathrm{HCO}_{3}{ }^{-} / \mathrm{CO}_{3}^{--}$) to a final print concentration of $100 \mu \mathrm{g} / \mathrm{mL}$. Additionally, rabbit IgG was twofold serially diluted $(100 \mu \mathrm{g} / \mathrm{mL}, 50 \mu \mathrm{g} / \mathrm{mL}, 25 \mu \mathrm{g} / \mathrm{mL}$, $12.5 \mu \mathrm{g} / \mathrm{mL}$ and $6.25 \mu \mathrm{g} / \mathrm{mL}$ ) into 50 $\mathrm{mM}$ carbonate buffer and printed at these varying concentrations. Print solutions were transferred into a 384-well polypropylene microplate (Corning Costar, Acton, MA, USA), and the plate was loaded inside the printer manifold. ELISAs were carried out using commercially prepared monoclonal antibodies dissolved in PBS to a final assay dilution of 1:1000 in Blocker Casein in PBS solution.

\section{Microarray ELISA}

Using an automated HYDRA ${ }^{\circledR} 96$ Liquid Pipettor (Robbins Scientific, Sunnyvale, CA, USA), wells on the 96-well microarray plate were washed consecutively $3 \times$ with $35 \mu \mathrm{L}$ of $1 \times$ Trisbuffered saline (TBS) $+0.1 \%$ Tween ${ }^{\circledR}$ 20 to remove excess unbound antigen. Nonspecific binding sites were blocked by pre-incubating with $50 \mu \mathrm{L}$ of Blocker Casein in PBS for $1 \mathrm{~h}$ at RT. After blocking, $25 \mu \mathrm{L}$ of the appropriate monoclonal antibody mixture (1:1000 in Blocker Casein) was incubated with an array at RT for $60 \mathrm{~min}$. A single, partial or complete cocktail mixture of all 8 monoclonal antibodies was added to appropriate wells.

Following primary monoclonal antibody binding, the HYDRA 96 was used to remove excess antibody solution from each well. This was followed by washing each well $3 \times$ with $35 \mu \mathrm{L}$ of $1 \times$ TBS $+0.1 \%$ Tween 20 . Secondary detection of bound antibody complex was carried out by incubating each well with $25 \mu \mathrm{L}$ of a 1:1000 dilution of streptavidin:alkaline phosphatase (AP) conjugate in $1 \times \mathrm{TBS}+0.1 \%$ Tween 20 for $20 \mathrm{~min}$. Excess conjugate was removed, and each well was washed $3 \times$ with $50 \mu \mathrm{L}$ of $1 \times \mathrm{TBS}+0.1 \%$ Tween
20. Array detection was initiated by adding $30 \mu \mathrm{L}$ of the fluorescent alkaline phosphatase substrate ELF for 5 $\min$ at RT. Excess substrate was removed and wells were rinsed in distilled water. Finally, the prepared microarray plates were allowed to air dry before imaging.

\section{Scanning CCD Imager}

The main components of the custom CCD imager include: a peltier-cooled Pixel Vision camera consisting of a SpectraVideo front-illuminated CCD camera that has an attached MicroNikkor $^{\mathrm{TM}}$ AF lens $(60 \mathrm{~mm}$ f/2.8D; Nikon, Melville, PA, USA). The CCD captures a $1 \times 1$ " image region $(1024 \times$ 1024 pixels), where each CCD pixel consists of a $24-\mu \mathrm{m}$ square area. The effective focal length of the imaging configuration is $20 \mathrm{~cm}$, which maps to a calculated magnification factor of 2.16 from the CCD to the image plane. The dynamic range of the CCD imager was determined to be $1.8 \operatorname{logs}$ using a stepped neutral density filter (Edmund Scientific, Barrington, NJ, USA) at a single integration time (i.e., $7.5 \mathrm{~s}$ ). UV excitation consisted of a 6-W long wavelength $(365 \mathrm{~nm})$ transilluminator light source (Spectronics, Westbury, NY, USA). Motion control consists of stepper drives (New England Affiliated Technology, Lawrence, MA, USA) and Compumotor 4-axis motion control system (Parker Hannifin, Compumotor Division, Rohnert, CA, USA), all contained on a custom cart and enclosure assembled from 80/20 Parts (Columbia City, IN, USA). The system is controlled by a $333 \mathrm{MHz}$ computer system (Dell Computer, Round Rock, TX, USA) with $256 \mathrm{~K}$ of random-access memory (RAM). All other fixtures and custom parts were manufactured in-house.

The CCD is mounted to a $\mathrm{Z}$-axis drive that positions the $\mathrm{CCD}$ camera inline with a single microarray plate before image acquisition. The associated plate-carrier tray is mounted to an $\mathrm{X}-\mathrm{Y}$ stage that provides loading/unloading and scanning of slides containing microarrays about the detection plane. The plate carrier tray accepts microarray plates held by a custom delrin insert holder that securely holds the $5 \times 3^{\prime \prime}$

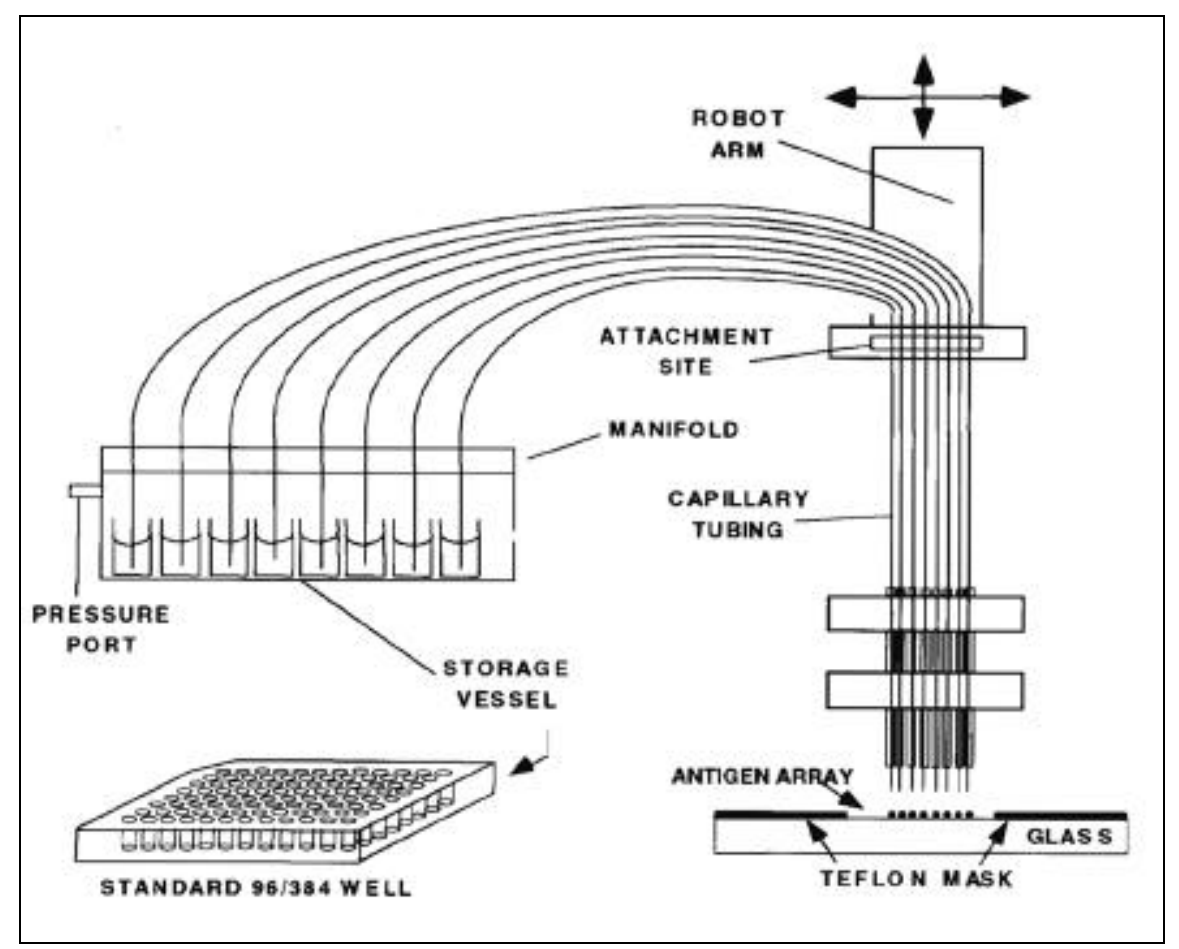

Figure 2. Schematic of protein array printer. Protein-containing solutions (10-200 $\mu \mathrm{L})$ are transferred into wells of a standard 96- or 384-well microplate. All antigen solutions are normalized to contain the same protein concentration (i.e., equimolar). The microplate is placed in the printer manifold, and the capillaries are primed with protein solution under nitrogen pressure. After priming is complete, computer-controlled contact printing of arrays begins. 
Table 2. Detection of an Entire Microarray Plate with Various Antibodies

\begin{tabular}{|c|c|c|}
\hline Column Number & Rows & Antibody \\
\hline Column 1 & $(\mathrm{~A}-\mathrm{H})$ & Anti-Guinea Pig Monoclonal \\
\hline Column 2 & $(\mathrm{~A}-\mathrm{H})$ & Anti-Chicken Monoclonal \\
\hline Column 3 & $(\mathrm{~A}-\mathrm{H})$ & Anti-Cat Monoclonal \\
\hline Column 4 & $(\mathrm{~A}-\mathrm{H})$ & Anti-Rabbit Monoclonal \\
\hline Column 5 & $(\mathrm{~A}-\mathrm{H})$ & Anti-Bovine Monoclonal \\
\hline Column 6 & $(\mathrm{~A}-\mathrm{H})$ & Anti-Goat Monoclonal \\
\hline Column 7 & $(\mathrm{~A}-\mathrm{H})$ & Anti-Rat Monoclonal \\
\hline Column 8 & $(\mathrm{~A}-\mathrm{H})$ & Anti-Human Monoclonal \\
\hline Column 9 & $(\mathrm{~A}-\mathrm{H})$ & $\begin{array}{l}\text { Negative Control } \\
\text { (No Monoclonal) }\end{array}$ \\
\hline Column 10 & $(\mathrm{~A}-\mathrm{H})$ & Mix of All Monoclonals \\
\hline Column 11 & $(\mathrm{~A}-\mathrm{H})$ & Mix of All Monoclonals \\
\hline Column 12 & $(\mathrm{~A}-\mathrm{H})$ & Mix of All Monoclonals \\
\hline \multicolumn{3}{|c|}{$\begin{array}{l}\text { The table details the biotinylated detection antibody or mixtures that were } \\
\text { incubated with each well on the microarray plate. All } 96 \text { arrays on the plate were } \\
\text { simultaneously incubated with a 1:1000 dilution of the indicated detection } \\
\text { antibodies. }\end{array}$} \\
\hline
\end{tabular}

teflon-coated glass plate.

The pre-described configuration allows the source microarray sector to be excited from the bottom of the plate and fluorescence emission detected from the top of the plate by the $\mathrm{Z}$-axis mounted CCD camera. A two-stage cover provides a light-tight enclosure, and an automated door allows plates to be loaded with conventional robotic arms. The scanning CCD imager is mounted on a custom mobile cart that houses the computer and stepper drive control components.

Total instrument control, including motion control and image acquisition,

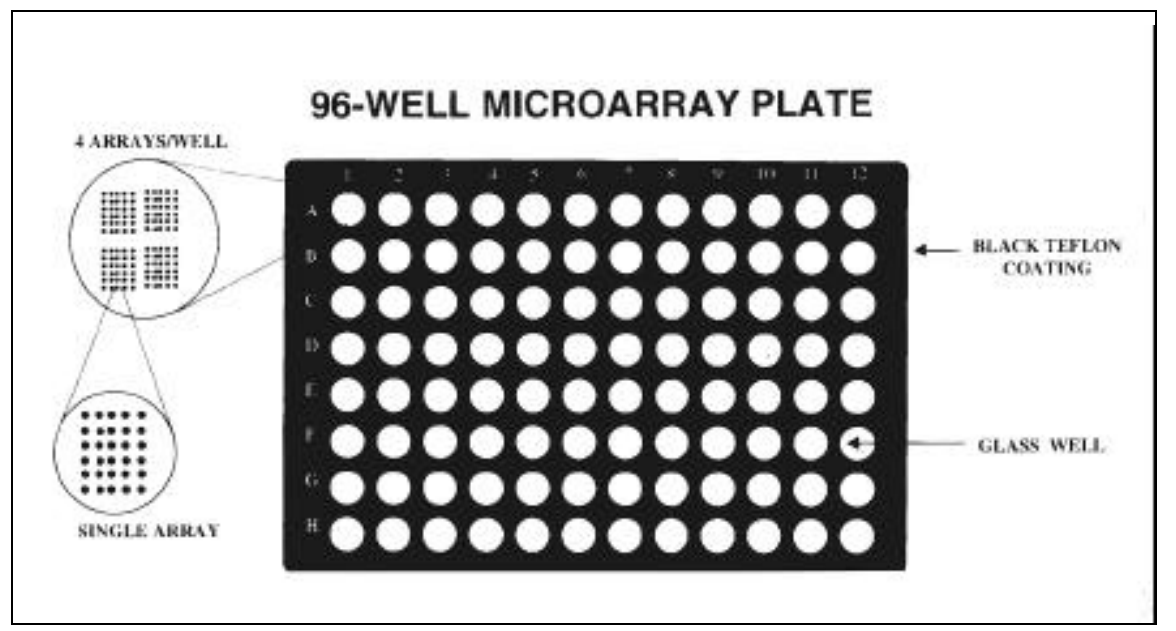

Figure 3. Schematic of a 96-well microarray plate. Each of the individual 96 glass wells contains antigens printed on its surface. Four identical $6 \times 6$ antigen arrays are printed in each well (144 elements per well) and serve as replicates to enhance assay validity. All arrays on the plate are identical to each other, forming a highly parallel assay format. 
is provided by GeneView ${ }^{\mathrm{TM}}$ Pro software (Genometrix, The Woodlands, TX, USA), complete with database and image-analysis tools. GeneView Pro is a user-friendly visual basic, multithreaded, graphical interface that utilizes OPTIMAS ${ }^{\mathrm{TM}}$ image processing tools (Media Cybernetics, Bothell, WA, USA) and Compumotor's motion control dynamic linked libraries (DLLs). GeneView Pro allows users to select automated or single sector image acquisition. The automated scanning feature captures 4 sector images for the 96-well slides. The resulting 16-bit (2.5-MB) images are saved to disk with a standard file-naming convention. Single sectors can be imaged by manually selecting the sector of interest. Ideally, single sector imaging can be used to set and save optimized CCD integration times before initiating full-plate automated image acquisition. A full microplate (containing 96 microarrays) can be imaged in 30 s using a 5-s integration time, which includes image retrieval and file archiving.

\section{Conventional CCD Camera}

A commercially available CCD camera system was used to generate low-resolution "pan" images of an entire 96-well array plate. The AlphaImager ${ }^{\circledR} 2000$ Digital Imaging System (Alpha Innotech, San Leandro, CA, USA) includes a light-tight enclosure containing a dual light (302/365 nm) transilluminator. The camera system consists of a high-performance CCD camera with $12.5 \times 75 \mathrm{~mm}$ zoom lens, close-up +2 diopter lens, interference filter and a Windows ${ }^{\circledR 95}$ (Microsoft, Redmond, WA, USA) computer system (Pentium $166 \mathrm{MHz}$ ). Image acquisition, enhancement and analysis software are all under AlphaEase ${ }^{\mathrm{TM}}$ (Alpha Innotech) control. Microarray plates were imaged using a standard transilluminator (UV $365 \mathrm{~nm}$ ) for $60 \mathrm{~s}$.

\section{RESULTS}

Standard ELISAs immobilize antigens or antibodies by passive adsorption to a plastic substrate (polystyrene). However, passive adsorption is not an efficient method of immobilizing proteins to glass surfaces. For this reason, 96-well glass microarray plates were first amino-modified using APTS followed by surface activation using a

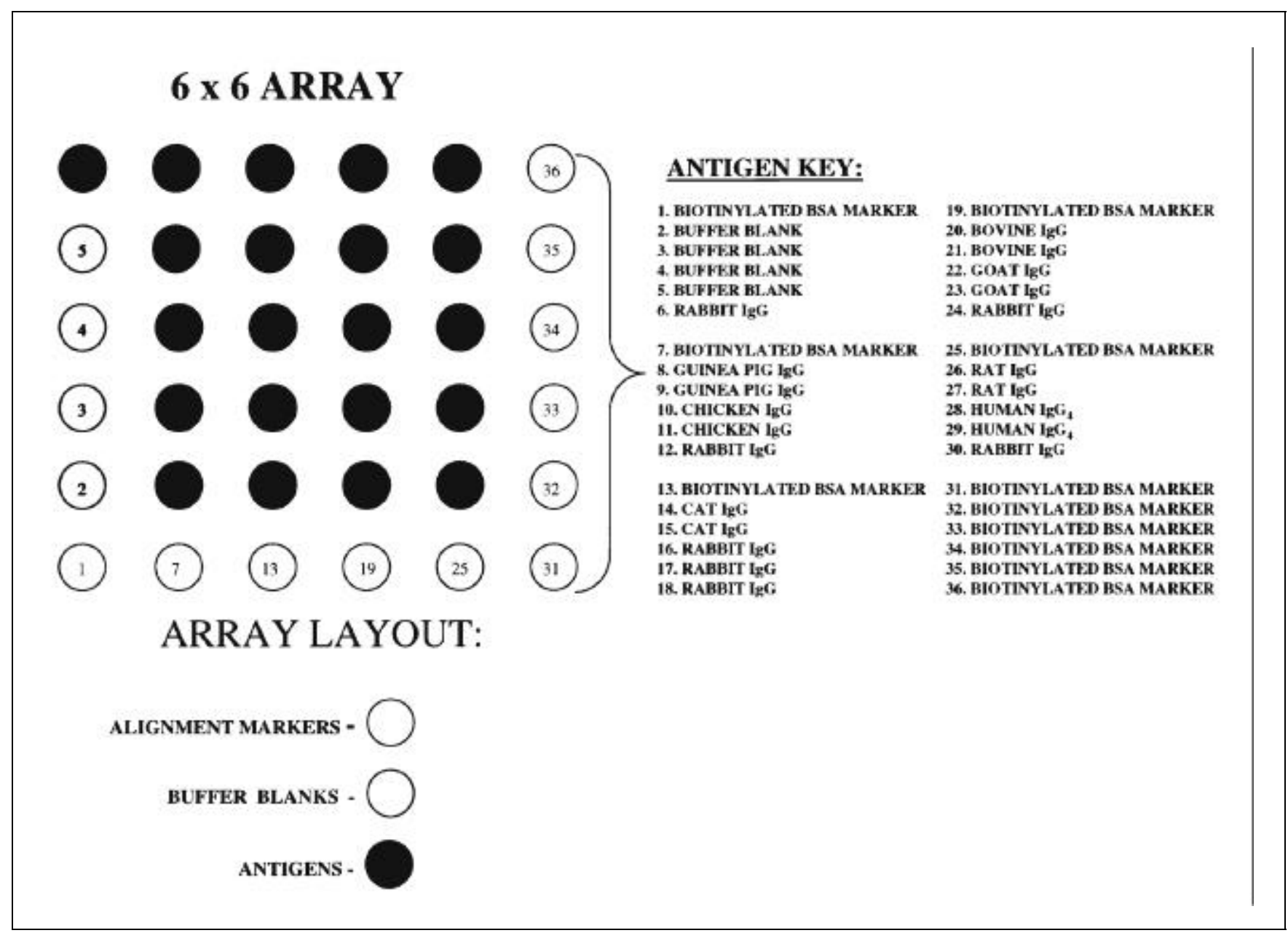

Figure 4. Array layout and antigen key. Printed antigen elements within each microarray are numbered in the layout. Numbers correspond to immobilized antigen as indicated in the antigen key. Note that some elements in the $6 \times 6$ array correspond to buffer blanks (carbonate buffer only). The remaining elements in the layout correspond to biotinylated markers, which permit spatial orientation of any given antigen relative to the markers. 
water-soluble homobifunctional NHSester. This NHS-activated surface was capable of efficiently immobilizing protein-based antigens. Figure 1 illustrates the ELISA format used in these experiments.

All protein arrays were printed using the continuous flow, capillarybased printer (Figure 2). Arrayed antigens consisted of purified polyclonal IgGs isolated from various animal sources (Table 1). The antigens were contact printed onto a 96-well glass microarray plate. This microarray plate is illustrated in Figure 3. Note that four identical $6 \times 6$ arrays are printed in each well. This simple contact redundancy (144 elements per well) executed by the robotic printer gives strong statistical confidence in assay results generated from each 7-mm well.

Figure 4 shows the spatial layout key for the antigen array. As seen in the figure, the entire first row (array elements $1,7,13,19,25$ and 31) and the last column (array elements 31-36) consist of biotinylated BSA markers. These markers allow unequivocal orientation of the array and identification of individual elements within the array. Printing of biotinylated marker proteins in each array also serve as a positive control for detec- tion reagents (i.e., streptavidin:AP conjugate and ELF). Additionally, individual antigen elements in each array are printed in duplicate.

After printing, an entire 96-well array plate was incubated with either single or multiple monoclonal antibodies to test specificity and multiplexing characteristics. To demonstrate the specificity of each biotin-labeled monoclonal antibody for its cognate antigen, each array column ( 8 wells per column) on the plate was incubated, after a blocking step, with its cognate monoclonal as outlined by the incubation regimen in Table 2. Other columns were incubated with either no monoclonal (negative control) or a cocktail mixture consisting of 8 different monoclonals. Antigen-antibody complexes were then detected using a streptavidin:AP conjugate and ELF as described in Materials and Methods.

The 96-well microarray plate was imaged using two separate imaging systems. The first system consisted of a low-resolution, commercially available CCD camera and a UV transilluminator (365 nm). This low-resolution camera system allows for a single pan image of all 96 arrays to be taken as seen in Figure 5. However, individual array

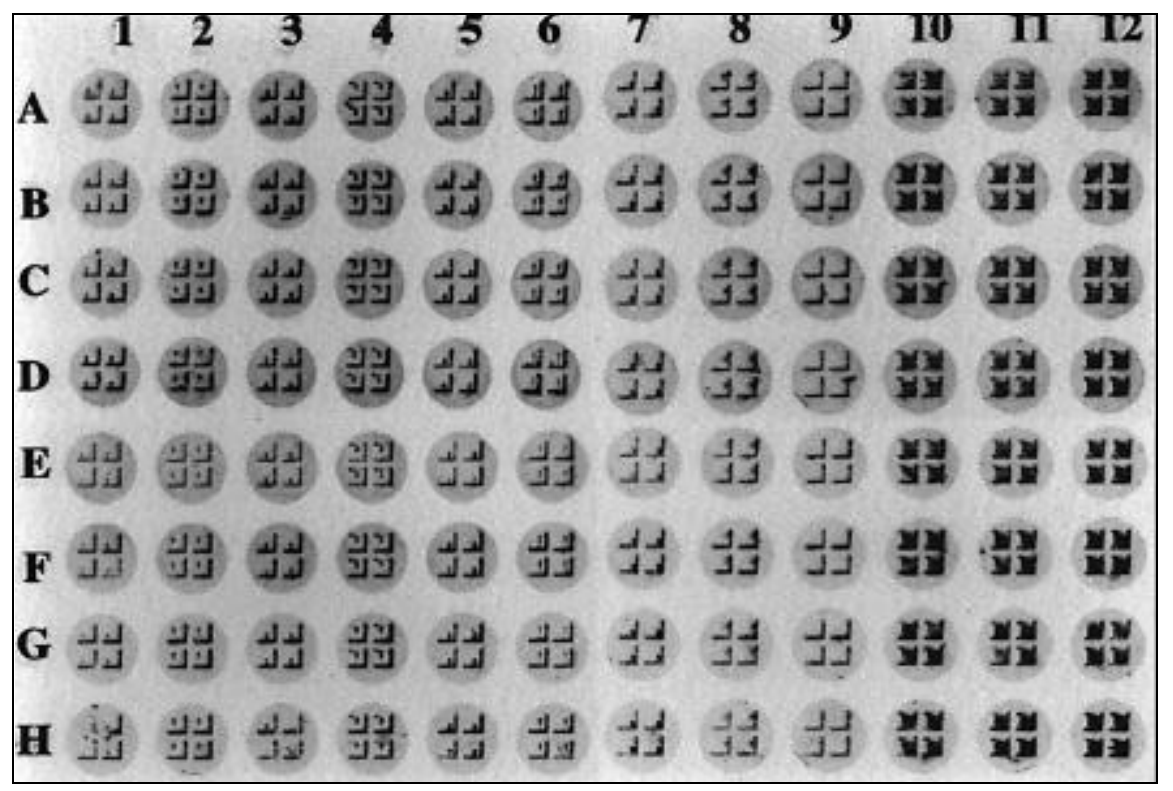

Figure 5. Low-resolution panoramic image of an entire 96-well microarray-based ELISA plate. Image was taken using a 60 exposure on the AlphaImager 2000 CCD Camera System. Array plates were excited using a standard transilluminator (UV 365) light source. Columns (1-12) and rows (A-H) use conventional microplate numbers and lettering. Each column was incubated with either single or multiple antibody mixtures as outlined in Table 2. Column $9(\mathrm{~A}-\mathrm{H})$ consist of wells incubated with Blocker Casein in PBS only (negative controls). 
elements cannot be resolved using this pan image.

To generate high-resolution images of individual elements within an array, we used the scanning CCD detector. Here, the entire plate is scanned under GeneView software control with the CCD imager taking a series of images across 4 independent sectors. Singlewell images can then be magnified using the software to resolve individual elements within each array. Specificity and/or cross-reactivity of each antigen in the array for its cognate monoclonal antibody (or mixtures) was readily seen from these high-resolution CCD images (Figure 6).

A separate 96-well microarray plate was used to measure general assay sensitivity using a single monoclonal antibody. Using this new plate, arrays were incubated in parallel with various dilutions of rabbit IgG-specific monoclonal antibody. Figure 7 shows parallel images of this dilution series.

\section{DISCUSSION}

This study served to evaluate the feasibility of immobilizing protein antigens on glass surfaces in a miniaturized format with a new type of array printer and specifically imaging the printed antigens in a highly parallel, multiplexed ELISA format compatible with high-throughput analysis systems. The critical element in designing a microarray-based ELISA is the potential for cross-reactivity when incubating different monoclonal or polyclonal antibodies with an array of immobilized antigens. Although monoclonal antibodies recognize a single epitope, it is possible that structurally related proteins might have similar epitopes. In these experiments, all the antigens consisted of polyclonal IgGs. Although these antigens were isolated and purified from different animal sources, they do share structural similarity. For this reason, some cross-talk between antigens was not entirely unexpected for these commercial antibodies. Even so, specificity was demonstrated using anti-guinea pig, anti-chicken, anti-cat, anti-rabbit, anti-bovine and anti-rat monoclonal antibodies for their respective antigens. However, slight cross-talk was

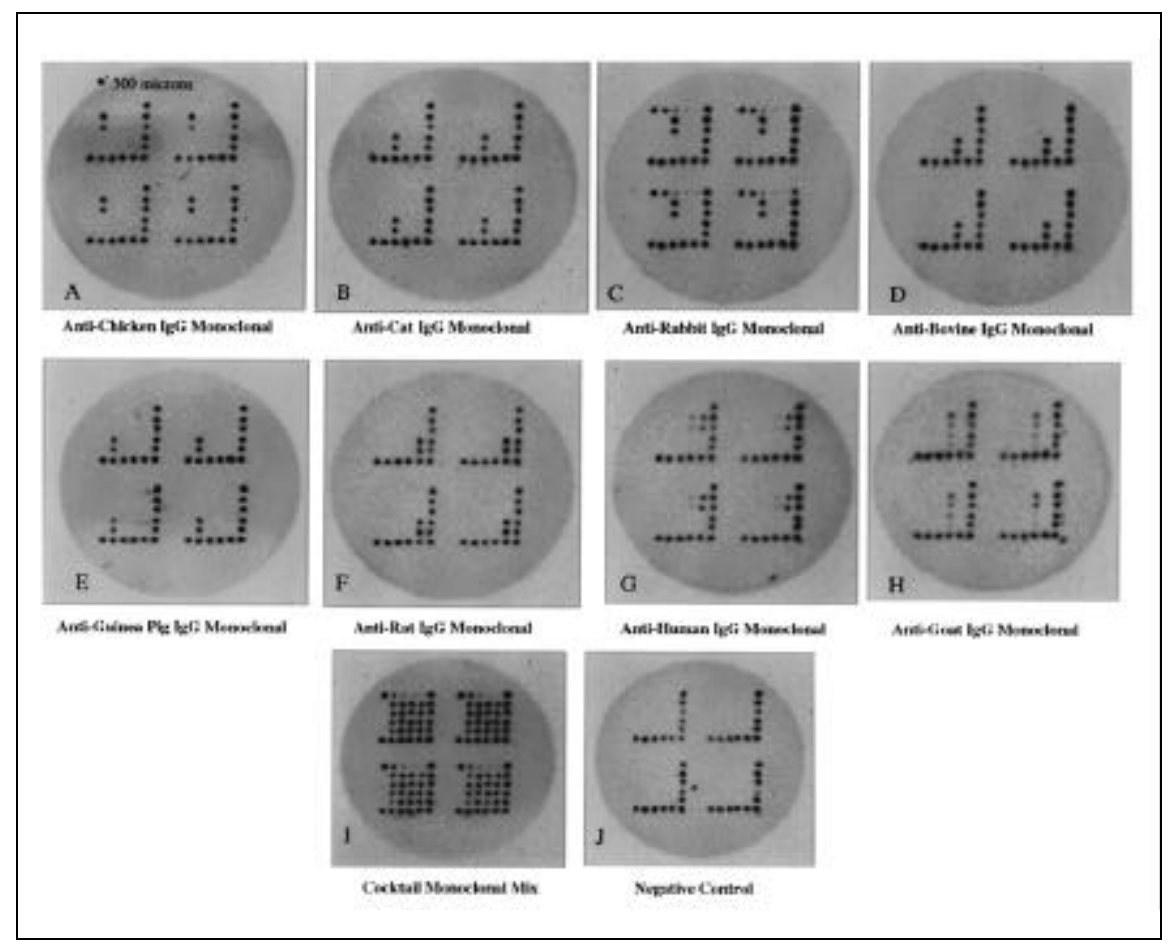

Figure 6. High-resolution CCD images of individual ELISA microarray wells. The panel consists of images A-J. All arrays were processed as indicated in the text under Microarray ELISA. Image A-H correspond to the detection of individual antigens by the indicated biotinylated monoclonal antibodies. Note that each well contains 4 identical arrays. Image I corresponds to the simultaneous detection of all antigens within the $6 \times 6$ array. Image $\mathrm{J}$ is a negative control incubated with streptavidin:AP conjugate. All images were taken using a 12 -s exposure at a CCD temperature of $273 \mathrm{~K}$.

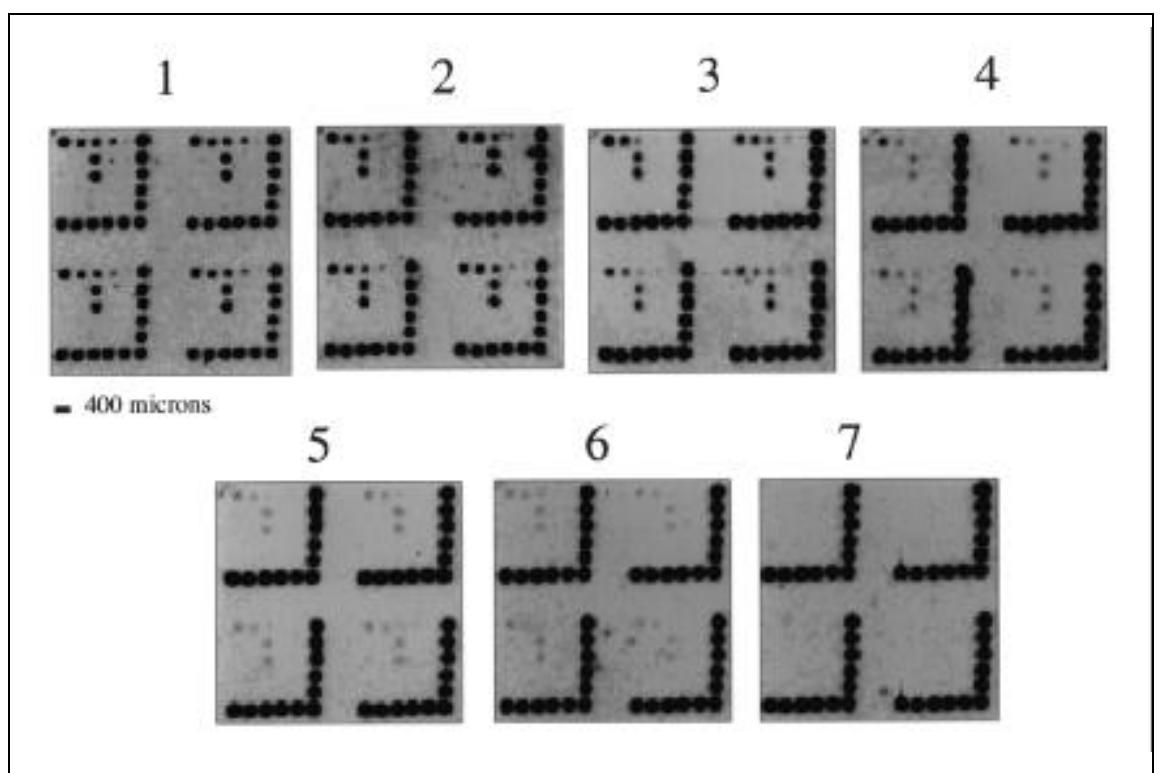

Figure 7. High-resolution parallel images of wells incubated with a serial dilution of rabbit IgGspecific monoclonal antibody. Seven parallel wells were incubated with $25-\mu \mathrm{L}$ volumes of the indicated dilution of biotinylated rabbit IgG antibody in Blocker Casein solution or Blocker Casein only (negative control). Images 1-6 correspond to a 1:25000, 1:50 000, 1:100 000, 1:150000, 1:200 000 and 1:300 000 dilutions, respectively. Image 7 is the negative control. The 1:300 000 dilution corresponds to a final antibody concentration of $13.4 \mathrm{ng} / \mathrm{mL}$. Arrays were incubated with substrate for $20 \mathrm{~min}$. Images were taken using a 12-s exposure at a CCD temperature of $273 \mathrm{~K}$. 
observed with both anti-goat IgG and anti-human IgG monoclonal antibodies. The anti-goat monoclonal had cross-reactivity with bovine $\mathrm{IgG}$, and the anti-human IgG antibody had slight cross-reactivity with goat IgG. An assay control that excluded incubation with secondary antibody but included incubation with the streptavidin:AP conjugate was negative across all arrays. These results suggest that successful multianalyte analysis using microarray-based ELISAs is strictly a matter of carefully screening each monoclonal antibody clone against all antigens on the array.

To evaluate ELISA sensitivity, a monoclonal antibody dilution series directed against rabbit IgG was used. This dilution series demonstrated that rabbit IgG antigen could easily be detected using a 1:300000 dilution of its cognate antibody (Figure 7). In this ELISA, the original rabbit $\operatorname{IgG}$ monoclonal antibody stock concentration was 4.1 $\mathrm{mg} / \mathrm{mL}$. This corresponds to an assay sensitivity of $13.4 \mathrm{ng} / \mathrm{mL}$ or $340 \mathrm{pg}$ of rabbit IgG monoclonal per well $(25-\mu \mathrm{L}$ total volume). ELISA sensitivity was limited by the fact that arrays were incubated with fluorescent substrate for only 5 min (i.e., far from the optimal signal generating incubation period [30-45 $\mathrm{min}$ ] recommended by the manufacturer). Lower detection limits were compromised because these preliminary arrays were not designed for maximum assay sensitivity. Rather, they were designed primarily to test the concept of multianalyte specificity. Detection sensitivity was compromised because of excess fluorescent backgound signal emanating from the biotinylated BSA markers used to define the perimeter of each array relative to the signal generated from the specific antigen. These marker sites generate a very large signal compared to the signal generated from the 1:300000 dilution of biotin-labeled secondary antibody for its specific cognate antigen on the array.

In retrospect, when designing future microarray ELISAs for high sensitivity, it might be preferable to use a secondary antibody for indirect detection of both markers and antigens. Indirect detection would allow signals generated from the markers to be attenuated simply by controlling the final dilution of detector antibody. This simple modification would permit long substrate incubation periods without excess background emanating from the markers. In these experiments, detection levels were not limited by detector sensitivity since the peltier-cooled CCD was capable of much longer integration times.

In summary, we have demonstrated the potential to conduct multianalyte assays using a new 96-well microarraybased ELISA format. All aspects of the process have been validated including high-speed microarray printing, antigen immobilization, ELISA specificity/sensitivity and automated microarray imaging. Monoclonal antibodies used to develop multiplexed assays must be carefully screened to avoid cross-talk between different but similar antigen sites on the array. When designing arrays, it may sometimes be necessary to screen several antibody clones for lack of cross-reactivity to other antigens on the array. Cross-reactivity on microarray-based ELISAs is analogous to crosshybridization signals seen between single mismatch DNA capture probes and their cognate target sequences.

Advantages of this new 96-well format include both parallel and multiplexing features. Print redundancy within each well adds greatly to visual confirmation of assay validity, and the open architecture format is fully compatible with high-throughput robotic liquid handling systems and automated microarray imaging systems.

In the future, it is likely that antibody-based microarrays will be used to directly detect protein expression products from crude cell lysates. It will be interesting to validate any such arrays against cDNA-based arrays that measure expression indirectly at the mRNA level. Finally, chip-based formats promise to increase clinical diagnostic throughput in cancer and infectious disease diagnostics while simultaneously reducing cost.

\section{ACKNOWLEDGMENTS}

We wish to thank Mike Hogan for careful reading of the manuscript. We would also like to acknowledge Bill Balch for his tenacity during the design of Genometrix's capillary printer.

\section{REFERENCES}

1.Chee, M., R. Yang, E. Hubbel, A. Berno, X.C. Huang, D. Stern, J. Winkler, D.J. Lockhart et al. 1996. Accessing genetic information with high density DNA arrays. Science 274:610-613.

2.Chiem, N.H. and D.J. Harrison. 1998. Microchip systems for immunoassay: an integrated immunoreactor with electorphoretic separation for serum theophylline determination. Clin. Chem. 44:591-598.

3.Ekins, R. and F.W. Chu. 1991. Multianalyte microspot immunoassay-microanalytical "compact disk" of the future. Clin. Chem. 37:9551967.

4.Ekins, R. and F.W. Chu. 1997. Microspot ${ }^{\circledR}$, array-based, multianalyte binding assays: the ultimate microanalytical technology? p. 625646. In C.P. Price and D.J. Newman (Eds.), Principles and Practice of Immunoassay, 2nd ed. Stockton, New York.

5.Gingeras, T.R., G. Ghandour, E. Wang, A. Berno, P.M. Small, F. Drobniewski, D. Alland, E. Desmond and J. Drenkow. 1998. Simultaneous genotyping and species identification using hybridization pattern recognition analysis of generic mycobacterium DNA arrays. Genome Res. 8:435-448.

6.Gushin, D., G. Yershov, A. Zaslavsky, A. Gemmel, V. Shick and D. Proudnikov. 1997. Manual manufacturing of oligonucleotide, DNA, and protein microchips. Anal. Biochem. 250:203-211.

7.Rowe, C.A., S.B. Scruggs, M.J. Feldstein, J.P. Golden and S.L. Frances. 1999. An array immunosensor for simultaneous detection of clinical analytes. Anal. Chem. 71:433-439.

8.Schena, M., D. Shalon, R. Heller, A. Chai, P. Brown and R.W. Davis. 1996. Parallel human genome analysis: microarray-based expression monitoring of 1000 genes. Proc. Natl. Acad. Sci. USA 93:10614-10619.

9.Schena, M., D. Shalon, R.W. Davis and P.O. Brown. 1995. Quantitative monitoring of gene expresion pattern with a complementing DNA microarray. Science 270:467-470.

10.Silzel, J.W., B. Cercek, C. Dodson, T. Tsay and R.J. Obremski.1998. Mass-sensing, multianalyte microarray immunoassay with imaging detection. Clin. Chem. 44:20362043.

Received 5 April 1999; accepted 15 June 1999.

Address correspondence to:

Leopoldo G. Mendoza

Genometrix

3608 Research Forest Drive

Suite B7

The Woodlands, TX 77381, USA

Internet: Imendoza@genometrix.com 